\title{
THE FIRST CASE OF THE ANTLEY-BIXLER SYNDROME WITH A CONSANGUINITY IN JAPAN
}

\author{
Yoji Yasui, ${ }^{1}$ Atsuko Yamaguchi, ${ }^{1}$ Yoshimoto Itoh, ${ }^{1}$ Tsuyoshi Ueke, ${ }^{2}$ \\ Kohachiro SugIYAMA, ${ }^{3}$ and Yoshiro WADA ${ }^{3}$ \\ ${ }^{1}$ Department of Pediatrics, Nagoya City Josai General Hospital and \\ ${ }^{2}$ Department of Orthopedics, Nagoya City Josai General Hospital, \\ Kitabata, Nakamura, Nagoya 453, Japan \\ ${ }^{3}$ Department of Pediatrics, Nagoya City University Medical School, \\ Kawasumi, Mizuho, Nagoya 467, Japan
}

\begin{abstract}
Summary Antley-Bixler syndrome has the specific features as brachycephaly, craniosynostosis, midface hypoplasia, depressed nasal bridge, proptosis, dysplastic ears, upper respiratory obstruction, radiohumeral synostosis, joint contructures, arachnodactyly, and femoral bowing and fractures. It is a very rare disease and only five cases have been reported. Its etiology and heredity are unknown. All reported cases were sporadic but present case has the cousinship marriage parents, suggesting genetic disorder of autosomal recessive type.
\end{abstract}

\section{INTRODUCTION}

Antley and Bixler (1975) reported the first clinical case as "trapezoidocephaly, midface hypoplasia and cartilage abnormalities with multiple synostosis and skeletal fractures." Subsequently, DeLozier et al. (1980) reported the second, rather mild case. Recently, Robinson et al. (1982) reported 3 cases with the syndrome finally being established. The present case is the sixth, with the first case occurring in Japan. It is important to report clinical details in order to obtain more knowledge concerning the genesis of this syndrome.

\section{CASE REPORT}

The subject is a female who was born normaly after 40 weeks and 2 days of gestation, and was $1,945 \mathrm{~g}$ in weight, $44.0 \mathrm{~cm}$ in height, $27.5 \mathrm{~cm}$ in chest circumference and $29.5 \mathrm{~cm}$ in head circumference at birth, and belonged to so-called a small-fordates infant. The father was 27-year-old and the mother was 23-year-old. Paternal 


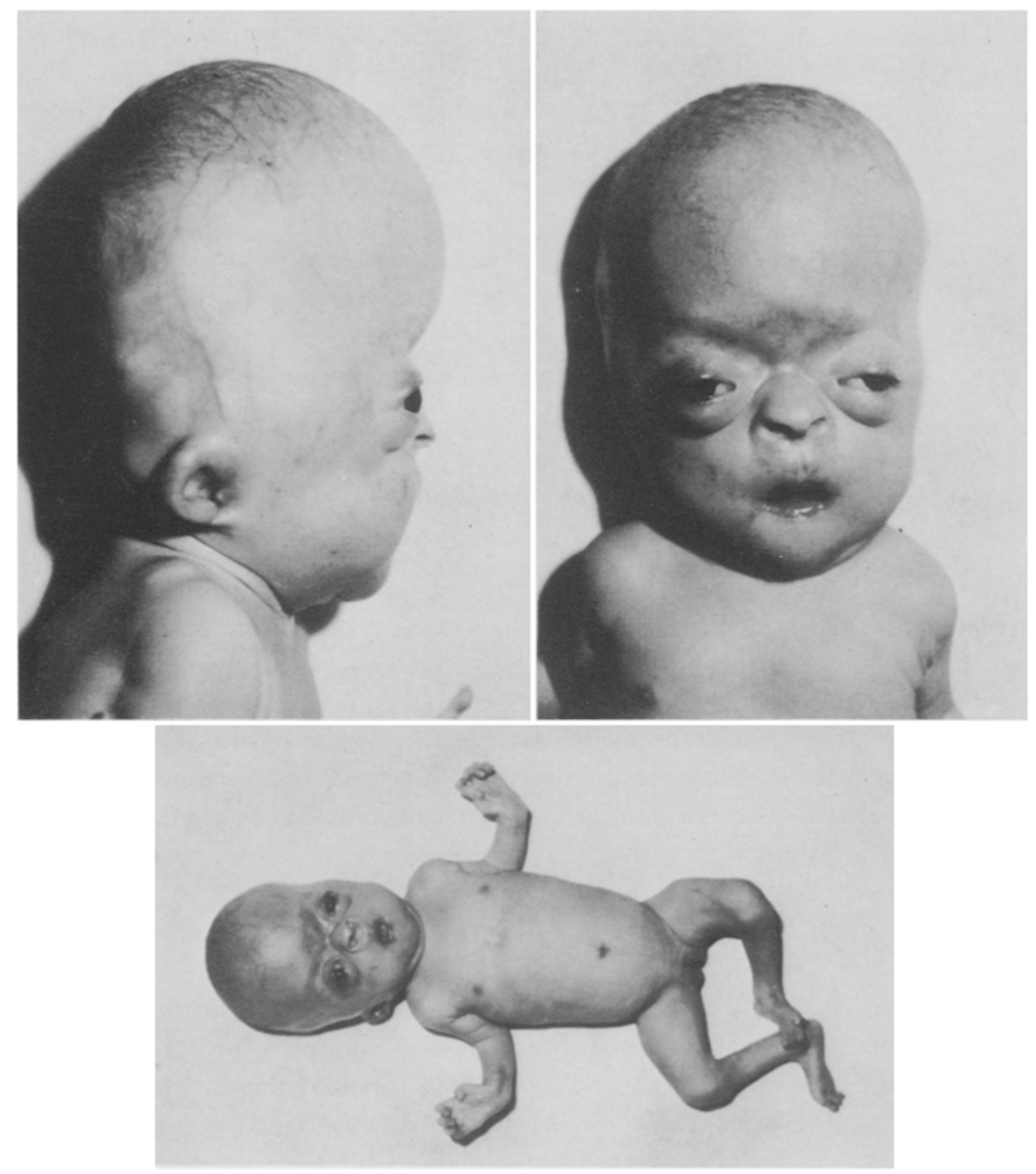

Fig. 1. Photographs on 10 th day after birth.

grandfather and maternal grandmother were brother and sister in the same family, that is the marriage of two cousins. No special abnormality was seen in the family history. Nothing special had occurred during pregnancy except that the mother took aspirins for 2 days at the 10th week gestation for fever due to infection of the upper respiratory tract.

The patient had brachycephaly, frontal bossing, craniosynostosis and cystic bone defect of the occipital, large anterior fontanelle, and also midface hypoplasia (severe depression of the nasal bridge, a prominent nasal tip, choanal atresia, large philtrum, small lips, a high and narrowly arched palate with a posterior creft palate, a small 
mandible) were observed. Low setting ears, a thick and rolled helix, and bilateral external auditory canals stenosis, arachnodactyly, hypoplastic or aplastic nails, a radially deviated thumb, partial cutaneous syndactyly, hypoplastic dermatoglyphs, poor subcutaneous tissue, hypoplastic genitalia, a sparse amount of hair (Fig. 1), weak and low crying voice, and insufficient milk sucking ability were observed.

Contructures of the elbow joints were seen, and radioulnahumeral synostosis were shown by her radiographs, and 2 carpal bones were seen in the both hands (Fig. 2), and bone age processed in tarsal bone was observed. Femoral bowing and fracture were also seen and increased permeability of X-ray was seen in the long diaphisis, rib and pelvis.

Hydrocephals and enlarged cerebral ventricles were observed by head CTscanning.

No heart abnormality was found by auscultation and ECG.

Radical treatment was not given because of the parents' requirement, and the infant was allowed to grow using only the self-feeding method.

At the 4 months old, and ulcer of cornea occurred due to insufficient closure of the eyelids because of exophthalmos. With the treatment was given the problem was corrected. Inflammation of the upper respiratory tract and of the middle ear was repeatedly treated.

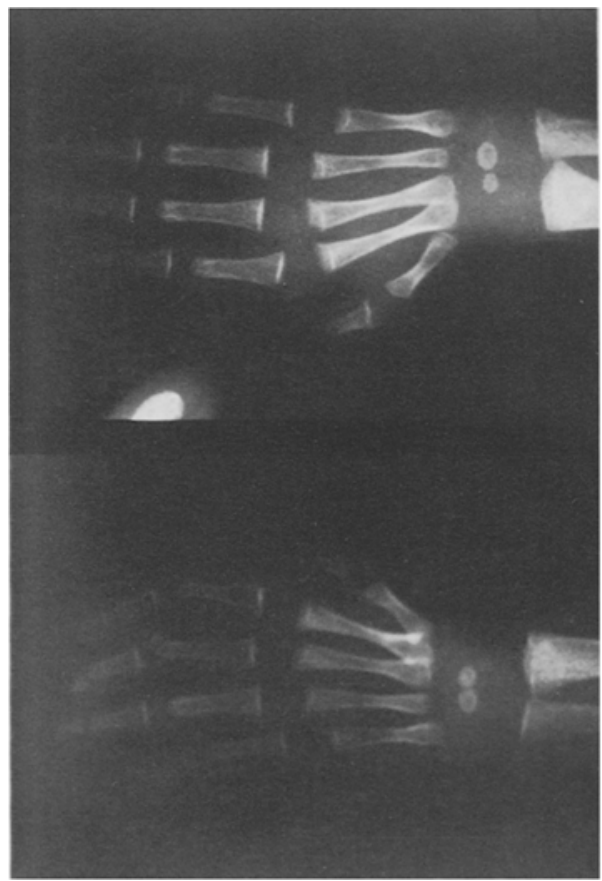

a

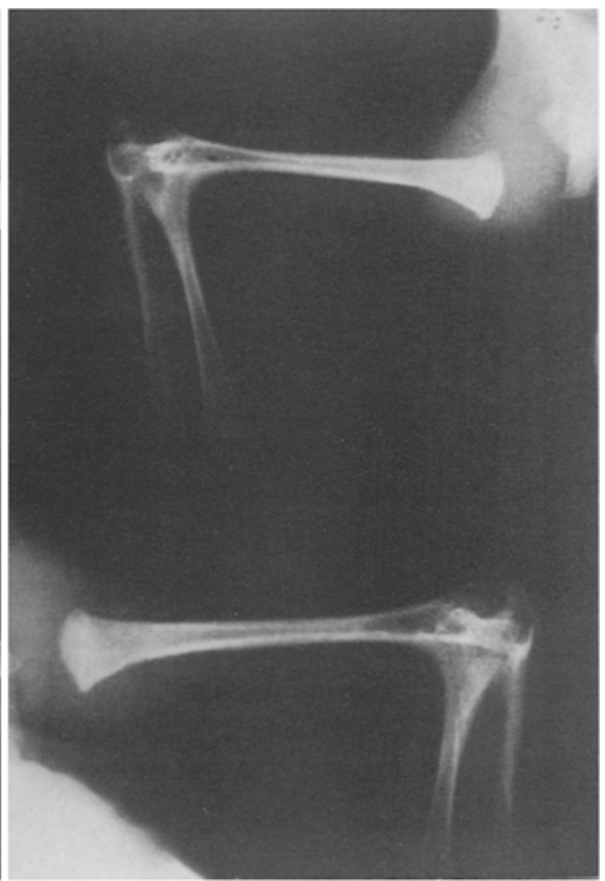

b

Fig. 2. a. Radiographs of bilateral radioulnahumeral synostosis on 8 th day after birth. b. Radiographs of carpal bones. 


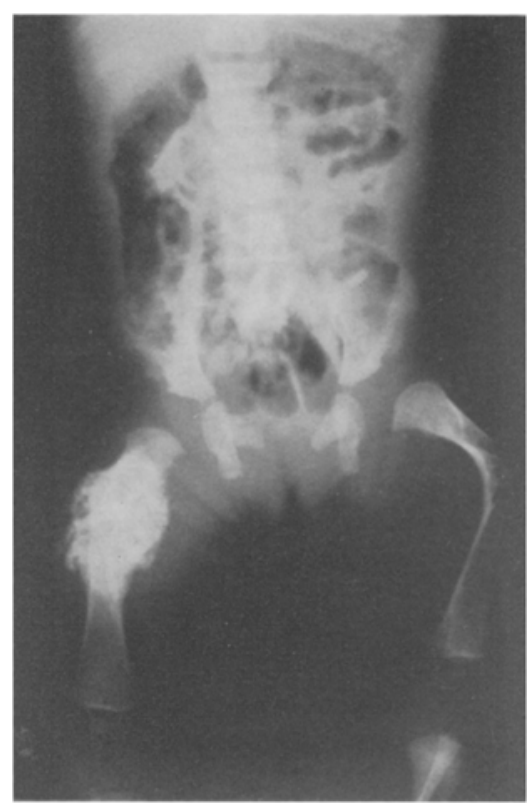

Fig. 3. Femoral bowing and fracture.

At the 7 months old, a marked retardation in growth was observed. The infant was only $3,240 \mathrm{~g}$ in weight, $52.5 \mathrm{~cm}$ in height, $31.5 \mathrm{~cm}$ in chest circumference and $46.0 \mathrm{~cm}$ in head circumference, but was allowed to leave hospital due to the request of the parents.

However, the infant died due to deglutition pneumonia and an autopsy was not performed.

No abnormalities were found in biochemical laboratory findings during hospitalization, except moderate increment of rubella CF titer $(\times 250)$. Chromosomal analysis showed $46, \mathrm{XX}$, normal female. Immunological examinations showed no abnormality in the humoral immune response such as $\mathrm{C}_{3}, \mathrm{C}_{4}, \mathrm{CH}_{50}$, and in the cellular immune response such as lymphocyte transformation test by phytohemagglutinin, leucoagglutinin, concanavalin A, and poke-weed mitogen.

Examination of the parents showed no abnormality in general blood analysis, radiographs of the bones and chromosomes, but the dermatoglyphic examination which showed a very similar loop formation in the interdigital $\left(\mathrm{I}_{4}\right)$ region.

\section{DISCUSSION}

The Antley-Bixler syndrome was established not so long ago, but no detailed pathological examination has been carried out probably due to the lack of clinical cases. 
The syndrome is characterized by brachycephaly, midface hypoplasia, dysplastic and low set ears, radiohumeral synostosis, joint contructures and arachnodactyly; and as DeLozier et al. indicated, differentiation of the syndrome from other similar diseases is not so difficult. When craniosynostosis, femoral bowing and fractures are found in addition to the above symptoms, a diagnosis may be confirmed.

However, there are various degrees of symptoms, from mild, as DeLozier et al. reported, to severe ones as Antley and Bixler, and Robinsons et al. reported.

Although 5 cases previously reported were appropriate-for-dates infants, the present case is a small-for-dates infant, and may be classified as the most severe type when compared with other symptoms.

The radiograph taken on the 8th day after birth is shown in Fig. 3. Pictures of a new fracture and its healing can be seen in the right femur, so as Robinson et al. indicated, femoral bowing seems to be due to an intra-uterus fracture. In our case, the appearance of 2 carpal bones was found on the 8 th day after birth as the first case of Antley and Bixler (1975), which indicated accelerated bone aging, while in the case of DeLozier et al. (1980) and the case 3 of Robinson et al. (1982) such bone aging phenomena were not seen, so that such a phenomenon might occur or not occur according to the individual.

All cases and symptoms of the previously reported cases are shown in Table 1 for future diagnostic reference.

Table 1. Features of the Antley-Bixler syndrome.

\begin{tabular}{|c|c|c|c|c|c|c|}
\hline \multirow{2}{*}{ Malformations } & \multirow{2}{*}{$\begin{array}{c}\text { Antley \& } \\
\text { Bixler } \\
(1975)\end{array}$} & \multirow{2}{*}{$\begin{array}{c}\text { DeLozier } \\
\text { et al. } \\
(1980)\end{array}$} & \multicolumn{3}{|c|}{ Robinson et al. (1982) } & \multirow{2}{*}{$\begin{array}{c}\text { Present } \\
\text { case } \\
(1983)\end{array}$} \\
\hline & & & Patient 1 & Patient 2 & Patient 3 & \\
\hline \multicolumn{7}{|l|}{ Craniofacial } \\
\hline Brachycephaly & + & + & + & + & + & + \\
\hline Large anterior fontanelle & + & - & + & + & + & + \\
\hline Craniosynostosis & + & + & + & - & + & + \\
\hline Midface hypoplasia & + & + & + & + & + & + \\
\hline Depressed nasal bridge & + & + & + & + & + & + \\
\hline Proptosis & + & + & + & + & + & + \\
\hline Dysplastic ears & + & + & + & + & + & + \\
\hline Upper respiratory obstruction & + & + & + & + & + & + \\
\hline Choanal stenosis/atresia & + & - & - & - & + & + \\
\hline \multicolumn{7}{|l|}{ Limbs } \\
\hline Radiohumeral synostosis & + & + & + & + & + & + \\
\hline Joint contructures & + & + & + & + & + & + \\
\hline Arachnodactyly & + & + & + & + & + & + \\
\hline Femoral bowing & + & + & + & - & + & + \\
\hline Femoral fractures & + & + & - & - & + & + \\
\hline
\end{tabular}

Vol. 28, No. 3, 1983 
In the congenital malformation syndromes, an infectible constitution is frequently found, and since we did not find any abnormality in either humoral and cellular immune responsivenesses, the repeated infections might be due to morphological handicaps with anomalies.

Concerning etiology, DeLozier et al. (1980) said, "bone and cartilage maldevelopment which results from a single embryonic defect, is probably of genetic origin." Although 5 previous cases were resulted from genetically unrelated parents, the parents in our case were cousins, genetically related. Since no abnormality was found in either of their families, autosomal recessive heredity was suggested as the genetic disorder. More cases should be examined in detail including enzymological studies of the bone metabolism in order to establish the etiology.

\section{REFERENCES}

Antley, R., and Bixler, D. 1975. Trapezoidocephaly, midfacial hypoplasia and cartilage abnormalities with multiple synostoses and skeletal fractures. Birth Defects: Original Article Series 11: 397-401.

DeLozier, C.D., Antley, R.M., Williams, R., Green, N., Heller, R.M., Bixler, D., and Engel, E. 1980. The syndrome of multisynostotic osteodysgenesis with longbone fractures. Am. J. Med. Genet. 7: 391-403.

Robinson, L.K., Powers, N.G., Dunklee, P., Sherman, S., and Jones, K.L. 1982. The Antley-Bixler syndrome. J. Pediatr. 101: 201-205. 